\title{
Mad Max: The Car and Australian Governance
}

\author{
Kieran Tranter ${ }^{1}$
}

'The last of the V8 Interceptors, a piece of history.'2

This paper argues that the car is an intimate aspect of the governance of Australia. The term governance is defined as the techniques used to know, order and manage individuals. 'Mad Max II: The Road Warrior' is used as a prism to separate out the roles that the car performs in governance. Three roles are identified - the car as identity, the car as myth and the car as power. Applying this framework to Australia reveals the car's complex involvement in Australian governance, from the knowing and ordering of others, to collective myths of possession and future prosperity, to the knowing of place from space, to the removal of indigenous children. The significance of the car means Australia can be characterised as the petrochemical, chrome plated cyborg republic of $\mathrm{Oz}$.

\section{Introduction: Governance and the Car}

This paper has its origins in two observations. The first is the obvious importance of the car in the daily lives of Australians, from transportation in cities ${ }^{3}$ and youth culture. ${ }^{4}$ Even in Australian cinema, George Millar's car focused Mad Max trilogy is widely considered a very significant foundation for the modern industry. ${ }^{5}$ The second observation concerns the stolen generation. The stolen generation refers to indigenous children removed according to assimilation policies and placed in institutions or white foster families. Unexpectedly, the car is also prominent in survivor's accounts:

The biggest hurt, I think was having my Mum chase the welfare car I'll always remember it - we were looking out the window and mum was running behind us and singing... ${ }^{6}$ 
The production and celebration of movies like Mad Max and the deployment of the car to control problematic individuals indicate that the car is more then an object that Australians use. Alternatively, the observations suggest that the car structures and rationalises how Australians are known, how they are ordered and how they are managed. In short the car appears intimately associated with Australian governance.

'Governance' is an imprecise term. Used generally it tends to describe the art or project of ruling. ${ }^{7}$ However, recently there has been a growing body of literature that has 'governance' as the express frame of reference. This literature examines the many systems, techniques and strategies, which know, order and manage individuals in populations. Drawing inspiration from Foucault's focus on the relations between disciplinary institutions, discourses on the wellbeing of individuals and the emergence of the modern state, ${ }^{8}$ recent studies have examined diverse subjects such as unemployment, ${ }^{9}$ the varied mentalities behind contemporary penal policy ${ }^{10}$ and the significance of military style police in Australian colonialism. ${ }^{11}$ A concept regularly used in these analyses is that of 'technologies;' either as in the 'technologies of the self' referring to the disciplines self imposed to attain a desired state, ${ }^{12}$ or as in 'social technologies' referring to the complex network of policies and institutions aimed at facilitating desired social outcomes. ${ }^{13}$ However, this paper is concerned with technology used in its more general sense. It looks at how the car, an actual technological object, relates to the knowing, ordering and management of individuals.

An important injunction needs to be mentioned. This exploration does not involve a survey of the 'meaning' ascribed to the car within Australian or even global culture. ${ }^{14}$ There is a significant rift in governance literature on the possibilities of merging governance with hermeneutics. ${ }^{15}$ Instead, the car will be examined on how it manages individuals through allowing specific knowledge, including self-knowledge, and facilitates specific orderings of the self, others and space. This is not a straightforward task. The lack of existing work looking at specific technological objects and governance means there are few established tools for this analysis. The danger is that without a defined framework to organise a study the analysis will become overtaken with details about the social history of the car or its cultural meanings without making 
the necessary links to the knowing, ordering and managing of individuals. A preliminary study in a simpler context is needed to refine the analysis before it can be applied to the wider vistas of the car and Australian governance. Such a simpler context can be found in the second instalment of the Mad Max trilogy the 1981 Mad Max II: The Road Warrior.

Mad Max II is widely celebrated as the quintessential Australian road movie. ${ }^{16}$ Its striped down emphasis on near wrecked Australian made cars, broken characters, efficient dialogue and the empty bush around Broken Hill in New South Wales provides a suitable prism through which to untangle and arrange the multiple roles that the car performs in governance. However, a second injunction needs to be mentioned. Beyond its obvious Australian context of accents, vehicles, landscapes and dead kangaroos, ${ }^{17} \mathrm{I}$ am reluctant to treat the movie as a direct insight into Australian society. The movie is used as a window through which to develop and refine the framework for analysing the car in Australian governance.

Therefore, the following paper is in two sections. The first section uses Mad Max II as a prism to separate out the roles of the car in governance. Three roles are highlighted car as identity, car as myth and car as power. The second section applies this framework to analysis of the role of the car in Australian governance.

\section{Section 1: Mad Max II, Refining the Framework}

\section{The Road Warrior}

The plot of Mad Max II can be summarised briefly. Having abandoned the remnants of civilisation in Mad Max by accelerating into the badlands, the second movie begins several years latter with Max (Mel Gibson) stumbling upon a permanent community. Max has spent the intervening years as a nomad, scavenging fuel, food and parts from wrecks and debris. In contrast the community appears to have remade society inside a fortified compound by producing oil. ${ }^{18}$ In parody of classic cinema genres the narrative quickly establishes itself as a Western ${ }^{19}$ - Max the troubled cowboy hero; the Gyro-Captain (Bruce Spence), the goofy side-kick; the inhabitants of the community, 
the settlers and honest town folk of the Wild West; the leader of the community, Papagallo (Mike Preston), the town mayor; the Interceptor, the super horse that all good cowboys are blessed with; and Humungus' horde, the murderous Indians. ${ }^{20}$ Papagallo's community is under siege. Surrounding it is Humungus (Kjell Nilsson) and his horde, demanding the stockpile of fuel and murdering anybody who leaves the sanctuary. Once Max gains entrance into the compound the narrative turns to escape. After several failed attempts, including a failure culminating in the destruction of the Interceptor, Max drives the community's petrol tanker in an attempt to breach the siege. The tanker draws Humungus' 'dogs of war' ${ }^{21}$ away from the compound allowing the community to safely leave. Ironically, when the tanker is eventually destroyed during the climatic chase scene, Max discovers that it was only filled with sand.

Commentators generally regard the movie as the retelling in punk post-industrial guise of the formation of civilisation through the social contract. ${ }^{22}$ In this light Papagallo's community can be seen as the nascent community threatened by the forces of violence and anarchy represented by Humungus. According to this reading Max plays the role of an unwitting messiah. ${ }^{23} \mathrm{He}$ is the consideration for the social contract; his sacrificial drive of the tanker distracts Humungus allowing the community to seek a more fertile home. However, this reading of Mad Max II, is both substantively and theoretically unsatisfying.

In terms of substance to regard the movie as an affirmation of the social contract ignores significant elements of the movie. Foremost, the dimensions of future and technology are not addressed. The movie is futuristic and post-apocalyptic. However, the apocalypse in Mad Max II is not nuclear. ${ }^{24}$ As the prologue relates '...you have to go back to a time when the world was powered by the black fuel and the desert sprouted great cities of pipe and steel...the thundering machine spluttered and stopped. ${ }^{25}$ This suggests a prolonged energy crisis leading to economic and social collapse. The paradox of this is the enduring importance of the car for Max's world. Again in the prologue the link is made:

On the roads it was a white line nightmare. Only those mobile enough 
to scavenge, brutal enough to pillage, would survive. The gangs took over the highways, ready to wage war for a tank of juice. ${ }^{26}$

The wastelands of Mad Max II have their origins in the failure of the internal combustion engine to ground a sustainable civilisation. However, the car retains vitality. The political economy is not marked by a return to simpler forms of energy, but the car in its industrial complexity remains the focus. ${ }^{27}$ The importance of the car is further registered on the biography of individual characters. Papagallo was an oil executive. Max was not only a highway cop, but his 'madness' arose from the murder of his wife and child by a motorcycle gang in the first movie where: 'in the roar of an engine, he lost everything and became a shell of a man. ${ }^{28}$

These substantive difficulties with reading the movie as social contract also have theoretical difficulties. Peter Fitzpatrick has recently explored the essential contradictions inherent in social contract theorising. He argues that the dichotomy between the pre-contract war of all against all and the post-contract civilisation is misleading. He suggests that for the warring parties to enter into the contract they must have possessed some hallmarks of civilisation; namely self-awareness and a means of communication. ${ }^{29}$ In short order had to pre-exist before the essential ordering of the social contract. This continuity of order can be detected in Mad Max II. Papagallo's community and Humungus' gang cannot be taken as representing order and disorder. Humungus' gang is distinctly ordered. It, just like Papagallo's community, is strongly hierarchical, if not military (there is evidence Humungus was an army officer). ${ }^{30}$ The gang possesses rituals and relations; admittedly violent rituals of torture and 'perverse' relationships characterised by homoeroticism and Sadomasochism. ${ }^{31}$ Consequently, to regard the movie as solely the retelling of the 'conservative fantasy' ${ }^{32}$ of the social contract is insufficient.

Instead, a more comprehensive reading of the movie tells much more about the relations between a specific technological object and governance. In particular the movie presents itself as a sustained mediation on how the car facilitates a certain knowing, ordering and managing individuals. Within the movie this knowing, ordering and managing occurs at three specific sites - car as identity, car as myth, car 
as power.

\section{Car as Identity}

Primarily, the car operates to frame the identities of the characters in Mad Max II. It is through this car identity that the characters are known and ordered. Knowledge of the characters, their tendencies, rank and allegiances, is visually linked to their vehicles. Max provides the archetype of this relationship. Max drives the Interceptor, a highly modified police pursuit vehicle. It is a 'piece of history' - yet it has been modified for its current role as a high-speed marauder with booby-trapped long-range fuel tanks and a huge 'bug-catcher' supercharger. Max, the ex-policeman, is similarly a piece of history. Just like the car he is modified. The loss of family and meaning in the wastelands has made him 'mad,' an unprincipled pragmatist whom in the opening scenes ignores the plight some roadside wounded. It is significant that only after the destruction of the Interceptor, when his identity as a road warrior is challenged, that Max's rehabilitation begins: 'and it was here, in this blighted place, that he learned to live again. ${ }^{33}$ This metonymical relationship is reflected in the other characters. The members and machines of Humungus' horde, the rival road warriors, are stylistically similar to Max and the Interceptor; punk leather but with actual, identifiable cars and trucks hiding under the metal rams, wielded armour and weapons. Humungus is different. His gym pumped body and S\&M mask indicate him as somehow unnatural. ${ }^{34}$ This is reflected in his machine, an ugly six-wheeled monstrosity. ${ }^{35}$ It is not a piece of mass production history that has been appropriated and modified, but a 'one-off,' a machine born into the new world of violent scavenging.

In contrast to the leather and material appropriation of the road warriors, Papagallo's community is different. Dressed in flowing robes of light colours and simple cuts, they were nicknamed 'Gucci Arabs' by the production unit. ${ }^{36}$ This urbanity is reflected in their vehicles, the most significant being a yellow school bus; the ultimate imagery of safety and the urban dream. Papagallo's role as the rival leader to Humungus is also coded in his vehicle. Like Humungus' Papagallo drives a vehicle that is a 'one-off,' that does not have a link to the past. However, unlike Humungus' six-wheel beast, Papagallo’s machine evidences a degree of beauty. Its silver bullet 
body is reminiscences of Grand Prix cars of the 1920s - speeding modernity into the future. ${ }^{37}$ It is through their vehicles that each character's tendencies and aspirations are known and also through their vehicles that they are ordered. The vehicles code whether they belong inside or outside the compound and also their status within each community. However, the car's role extends beyond that of knowing and ordering characters through their identities. The car also underpins how the characters are ordered and managed through community grounding myths.

\section{Car as Myth}

In Mad Max II characters are ordered and managed through specific car based myths. The central myth within the movie is the myth of future prosperity told by members of Papagallo's community. The community dreams of a better future. They desire to go north; the 'voice in the wilderness' urging them on is a bikini model on a postcard for the Gold Coast. ${ }^{38}$ This northern nirvana is described to Max as 'paradise' where there is nothing better to do then 'breeeeed.' This collective dream of water and breeding orders the community through providing a collective goal and explains the community’s submission to Papagallo’s management. The myth justifies the existence of the compound and their oil refining. It also explains Papagallo's more Machiavellian decisions such as his sacrifice of individuals to Humungus and his hiding the full details of the escape plan from Max. He needs to manage individuals, to make the hard choices now, in order to provide for a better future.

This myth is based on the car. The car must not only transport the community from the compound to the northern paradise, but symbolically links the dark present of entrapment and danger to the promised future of peace and prosperity. The car plays the role of a sacred vessel consecrating the community through linking it to the promised land; providing communion of man, machine and myth. ${ }^{39}$ Given this mythical role of the car it is fitting that the community's messiah is a road warrior. The car as myth provides for the ordering of individuals as a community and their management. This mythical role of the car suggests a further role of the car in governance, as a direct instrument of power in the management of individuals. 


\section{Car as Power}

The final role of the car in Mad Max II is as an instrument of power in the management of individuals. Here the car, as a technological object for transportation, is directly utilised in the management of individuals. This occurs in the ordering and management of space by individuals and in the direct control over individual bodies.

The basis for the car's mythical role is its ability to control distance and to render it comprehensible. As such the car allows an individual to order space, to divide it into familiar places, useable resources and hostile spaces. As such the individuals in Papagallo's community need not identify their desert compound as home. The surrounding land is seen merely as an obstacle, full of danger and hostility that must be traversed. The car allows an individual to order the space surrounding them in such a way as to deny any attachment to the local environment. Instead, it allows individuals to dream of better places elsewhere. Further, these individual orderings, allows the possibilities that individuals can be managed to strive for that better place.

However, the car manages individuals more directly than through individuals' ordering of space. It directly manages individual bodies. The car can take, it can bring, it can contain and it can kill. Humungus' blockade depends on his road warriors chasing and killing any escapees, leaving their bodies violated and broken beside their violated and broken machines. The primary conflict of the movie, between Papagallo and Humungus for the refined oil is a battle for the bodies of their followers. In the world of Mad Max II oil creates a future, not just for the individuals in each camp, but for each community. However, the most obvious example of the car managing an individual is the crucifixion scene. An escaped colonist is returned to the walls of compound screaming and pleading for Papagallo to compromise with Humungus. The cause of his agony is obvious. Not only has the car captured him and returned him to his origin, but his body has become part of it. This scene directly shows how effective the car is in the management of individual's bodies.

The crucifixion scene also conveniently summarises how the car facilitates the knowing, ordering and management of individuals in the movie. In it the road 
warriors' identity as violent marauders is affirmed through the use of their vehicles for torture. The cars mythical role is implied in its use as a sacrificial altar. In chasing, catching and returning the escapee the car's ordering of space is celebrated, and in mutilating and killing him there is no doubt of the car's direct power over individual bodies. What emerges from this discussion of the car and governance in the movie is a three level analysis to examine the car and governance in Australia. Specifically, it suggests looking at how the car as identity allows certain types of knowledge about individuals and allows certain types of orderings. Further, it suggests looking at the role of the car as myth in the ordering and managing of individuals. Finally, it suggests examining the car as power in how it manages individuals through their conceptions of space and as a direct instrument in the control of their bodies.

\section{Section 2: The Car in Australian Governance}

\section{Australian Identities and the Car}

The first element of the car in governance to be examined is the role of the car in the knowing and ordering of individuals. When applied to Australia it becomes clear that the car is significant in how Australians know and order each other, in turn this knowledge and ordering allows direct management of individuals.

Like Max in Mad Max II, the 'hoon' is the archetype for the car in Australian identity. The dimensions of the hoon are well established. They are young working class males from the suburbs surrounding the large cities living out the masculine project of risk, speed and technical proficiency through the modification of older family sedans and public displays of dangerous driving. ${ }^{40}$ Cars are fundamental to hoon culture. The cultural hierarchy of better cars, the tribal affiliations to Ford or General Motors Holden, the associated cultural icons of the Bathurst 1000 Motor Race, Street Machine magazine and the annual and often riotous Summer National Street Machine Convention in Canberra, means that cars, the driving of cars, being a passenger in cars, repairing and modifying cars, and saving for a certain car or accessory is a bedrock on which life meaning and self identity is based. In Walker's interviews with young men from western Sydney one of her respondents indicated: 
Yes, a Ford man since I was knee high to a hubcap...I'll stick to Fords. Hopefully my kids will be with Fords. There's nothing better, nothing better then a Ford. I've wanted a Ford V8 since I was four years old. ${ }^{41}$

However, this centrality of the car for identity is not limited to the male hoons of the collective western suburbs. The car is also fundamental to identity across many cultural demographics. Jones sees the pursuit of 'lapping' the CBD of regional centres as a female activity. ${ }^{42}$ She notes that young women are often the drivers of cars, and through her interviews with young women from rural Tasmania perceives that for her respondents the car represents a safe place where genuine socialisation can occur away from alcohol and pubs. It is not surprising that the respondents rated the car as their most coveted object. ${ }^{43}$ Nobel and Baldwin share Jones' conclusion that car identity is gender inclusive. Through a scattered semiotic survey of cars, drivers and bumper stickers in Sydney they found that 'the car has become a symbol of female breaking out. ${ }^{44}$ They reflect on the level of sexual assertiveness, crude humour and aggression in the bumper stickers of cars driven by women. Through slogans such as 'Eat My Pussy,' continual self reference as a bitch (Bad Bitch, I am Bitch...) and 'One Sly Chick, ${ }^{45}$ young women in particular are seen as appropriating sexist repertoire for own forms of self-affirmation. Again it is the car as billboard, as the stand-in for the self that performs the role.

This car based identity is not limited to young Australians but also the aged. Lefrancöis documents that for the aged the car operates as a symbol of the active social self and a meaningful life. He suggests that the 'strong positive attitudes towards driving...may be viewed as a means of self actualization, that is to maintain autonomy and freedom. ${ }^{46}$ For the aged the revoking of a drivers licence becomes a sign of the decline to death, the end of independence and the becoming a social burden. The car is also important for the identities of indigenous people. The ABCTV Bush Mechanics series portrayed the importance of the car for the identity of indigenous men. The series showed the car as not only an essential instrument in the maintenance of cultural and community life, but the ability to be a 'bush mechanic,' to keep vehicles going when missing wheels, engine parts or most of the body, is highly 
prized and a significant source of community status. While the series humorously tells many stories about contemporary indigenous life in central Australia and the material disadvantages facing indigenous Australia, its popularity rests on its cavalier celebration of car culture, a celebration resonant with the wider Australian culture. ${ }^{47}$

These examples show that for many Australians their identity is closely tied to the car. Like in Mad Max II this car as identity facilitates knowledge about the individuals in the car. While most Australians could not tell a 1974 Holden Kingswood from a 1984 Ford Falcon, either car full of 20 year-olds in the inner city on a Thursday night triggers a shared body of knowledge about the occupants; from employment status, education level history, postcode of residential address, ethnic origin, criminal tendency, attitudes towards women, gays, refugees and consumer preferences. ${ }^{48}$ Whether true or false this car based knowledge allows Australians to order other individuals, to put them in their allotted place. This knowledge and ordering through the car can be repeated - the late model Mitsubishi Pajero jostling for space outside a private school; the utes lined up outside the country pub; the shaven middle age male in a new white Toyota Camry; the Mazda E2200 van with red mobile telephone numbers painted on the side. Each car allows the driver to be known and ordered middle class mother, jackaroos, bureaucrat, and tradesperson.

The significance of the car for Australian identities allows Australians to know and order individuals through their car. However, this knowledge and ordering is not limited to personal domestic assessments. It allows the management of individuals at an institutional level. At an immediate level certain cars, particularly models favoured by hoons and other 'deviant' groups, attract high levels of surveillance and police attention. This attention is also directed towards drivers that are not in the type of car that the general knowledge expects them to be driving. Government welfare officers often inquire and comment on the type and condition of the car as evidence of the individual's suitability for assistance. However, this management goes beyond the regulatory apparatus of the state. At a more diffuse level the car manages individuals through constituting lifestyles and consumer preferences. The car regularly features in advertising for products and services that have only a tenuous connection to the car. Here the knowledge of individuals provided by the car allows certain cars to represent 
the target demographic; a sensible Korean hatchback for first home-buyers, large fourwheel drives for retiree investment funds, the nimble European sedan for stylish executive wear. The car is packaged with the advertised product as part of a desirable lifestyle.

In summary the relation between the car and Australian identities allows individuals to be known and ordered. This knowledge and ordering goes beyond the assessments by individuals of other individuals they met on the road, and directly informs state management. Further still this knowledge allows individuals to be managed through the directing of consumer choice and delineating lifestyles. This last dimension of the car as identity flows into the second role of the car in governance, the car as myth.

\section{The Car as Myth of Australian Future}

The second role for the car in Australian governance identified in Mad Max II is its mythical function in the ordering and managing of individuals through collective myths of future prosperity. Here the car maintains a sense of Australian community through an elaborate myth of future prosperity and possession. This can be examined at two sites. The first is importance of the car in the emergence of 'modern Australia.' The second is the private dream of travelling around Australia in retirement.

The emergence of a national sense of Australia in the 1920 corresponds with the arrival of car. For Knott and Clarsen there is more to this relationship than coincidence. Knott examines how the car featured in Australian literature from this period. He argues that the car represented the emergence of modern Australia. The car's promise to overcome the hostile, alien, Australian bush made it seem like the victory weapon in the colonial battle. ${ }^{49}$ With the bush controlled the colonial period would give way to a better future, a prosperous modern future of social advancement

founded on technological solutions. ${ }^{50}$ A specific example of the mythical role of the car can be seen in Clarsen analysis of Marion Bell's 1926 'round Australia' journey. The high public profile given to Bell and her daughter's circumnavigation made real the car as myth - in carrying two women ${ }^{51}$ around the continent the car seemed to make good its promise of facilitating a modern Australia based on a technological 
'cultural possession' that would lead to an prosperous future. ${ }^{52}$ Here the car as myth established a national community ordered and managed to achieve a shared future. The car becomes a cipher to order individuals as either backward looking colonials with romantic notions of the land and the horse or true citizens of modern Australia. Further, the promise of the myth opens up new vistas for the management of individuals, the myth provides for a community that sees a shared future in the ordering and managing of themselves and others in the achieving of a modern future. And the car is not only the vehicle through which the promise land will be achieved. Through the managing of larger tracts of land, better communications, quicker delivery of services, better responses to natural disasters, more sophisticated responses to social problems, the car becomes the emblem for that promised and promising future.

The car can be seen to play a parallel mythical role in the private life of many Australians in the popular aspiration to be a 'grey nomad.' A grey nomad characterises older Australians 'taking to the road' or 'travelling north' in retirement and semi-retirement in a four-wheel drive and caravan. They represent a life goal for many Australians. People plan to become grey nomads, once work has settled down or the kids are off their hands. This desirability reflects a story of future prosperity, an ability to afford an expensive car and the financial freedom to go travelling for extended periods. In addition seeing the 'real Australia' reflects strongly Clarsen's view that 'cultural possession' is grounded on travelling around the continent. It plays out the link between seeing the 'real Australia' and ones-identity as a 'real Australian' as someone who has seen diverse parts of the continent and has authority to speak as an Australian. ${ }^{53}$ David Williamson's play Travelling North captures the justification for retirement nomadism in an opening exchange between Frank and his companion Francis:

Frank...We'll travel all over the North. You've had a hard struggle bringing up those daughters of yours and its time you started to enjoy life... ${ }^{54}$

This mythic role of the car in Australian governance lies in bringing together 
individuals as a community aspiring to possession and future prosperity. It not only orders Australians but also provides for those shared goals to be managed towards. It is public in the sense of a key element in the dreaming of modern Australia and private in the sense of an individual's ordering and managing of their own life. This mythical dimension of the car can be seen as a complex elaboration of the myth of Papagallo’s community in Mad Max II. However, as in the movie this mythical role of the car is based on its technological function, its power over space and individuals.

\section{The Car as Australian Power}

The next role of the car in governance identified was in the ordering and managing of space and facilitating specific forms of control over individual bodies. In Australia the car as power emphases the importance of the car in demarcation of space and control over Australian bodies.

As anticipated in the examination of the car as identity and the car as myth the car's role is grounded on its function as transportation. As transport technology the car allows individuals to order space in specific ways. For most urban Australians the car is structurally preordained as the mundane tool of everyday life. ${ }^{55}$ The very layout of Australian cities with suburbs linked to feeder streets, linked to arterial roads, linked to freeways, means that from shopping to leisure to work and schools, space becomes reduced to familiar nodes connected via anonymous roads. ${ }^{56}$ The car splits reality into two spaces. ${ }^{57}$ The first is the familiar living room of the vehicle's interior; a space made place through the accretion of objects and debris of the driver's life. The second is the space beyond the front fender - the empty, public space of the road - through which the car must be navigated so as to arrive at the next familiar place. ${ }^{58}$ In this context the car operates as a transit cocoon zapping the occupants across space and time to the next life node. This linking of car, space and time continues in rural areas where the common measure of distance is hours driving. In turn this demarcation of space and place facilitates the ordering of individuals. The car allows a dual life where relations with the public, whether others or nature, can be reduced to observations through laminated windscreens. Even the grey nomads maintain an Australianism based on 'seeing' the country. This disengaged, visual polis is the legacy of Australian 
governance given the car's power over space. Individuals in the public are transformed into others occupying a non-place needing to be watched, avoided and managed.

The car, in allowing an ordering of space that distances the public, manifests the ultimate role of the car as power, its direct control of Australian bodies. This can be read at several levels. Mundanely, the car's essentiality in daily life means that for most Australians significant potions of the day is spent behind the wheel, where they are known, ordered and managed within the urban grid. Additionally, the need for car ownership, to make the distance comprehensible in terms of place and space, means individuals are trapped in a certain frenzy of economic activity so as to afford the car lifestyle. The traces of these orderings can have physical evidence. Accidents happen and many Australians have the scares and mementoes inscribed on their bodies. ${ }^{59}$ The crucifixion scene in Mad Max II becomes iconic, an explicit recognition that for Australians the importance of the car in governance means a sacrifice of not just time but health, flesh and blood. However, this linking of cars, power and bodies within Australian governance has other dramas.

The programs that involved removal of indigenous children needed the car. They were a direct attempt by modern Australia to solve outstanding colonial difficulties. The continual existence and ongoing social problems of indigenous people challenged modern Australia both in its assertion of cultural possession of the continent and in the future promise of prosperity. ${ }^{60}$ The car's promise of technological solutions to social problems made the taking of children, in small, quiet and discrete ways possible and desirable. However, the car played a greater role then just an indicator for the policy potential of assimilation. From the 1920s through to the 1970s and beyond the car was the essential tool in the taking of individuals away from their family:

...Mum was at the door, and there was this car on the road outside. There was this white woman standing there...One minute we was coming home to the house, and the next instant we was in the car and gone. ${ }^{61}$ 
The tailgate was slammed shut and bolted and the truck screeched off with things hanging over the back and mothers and other children running after it crying and wailing. ${ }^{62}$

In survivor accounts the car come to represent the arrival of white authority and the end of family:

I still can’t remember some of the time when I was taken away and placed in Sister Kate’s Home...However, I do remember a big, black shiny car pulling up with a lady and a man in it... ${ }^{63}$

In many accounts the car itself is given the role as the active agent in the removal of family. For 'William' one of his earliest memories was his mothers funeral 'I can remember this utility with a coffin on top with flowers...I saw it get driven away knowing there was something inside that coffin that belonged to me. ${ }^{\text {,6 }}$ Similarly 'Peggy' keeps seeing an Aboriginal woman outside the fence of the home who claimed to be her mother: 'To me she was just a woman who comes and goes. When I was 5 she went again...I remember the night taxi pulled up to take her. ${ }^{65}$ The car also reappears in the lonely stories of interaction and rejection by white foster parents:

they [the foster parents] led me away... down a paved street where lots of different coloured cars were parked in a row. I even saw a Ute...This was green in colour...I kept looking around for my brothers... as I didn't want to go anywhere without them. I was told to sit in the back seat of a yellowish, cream-coloured car. ${ }^{66}$

...the biggest shock in my life came when they got me to get in the car, which was an old T-Model Ford with the running boards and all, and I was sitting in the car and I happened to look in the back seat and saw all my dolls sitting up. ${ }^{67}$

Finally, for the family remaining behind the car came to symbolise the trauma of loss: 
I remember that she [our mother] came in the truck with us curled up in the foetal position. Who can understand that, the trauma of knowing you are going to lose all your children. ${ }^{68}$

In Elaine Lomas’ poem an old women is returned to the day of the taking:

She screamed and she wailed as she followed the car, but dust in her eyes she couldn’t get far. ${ }^{69}$

This means that the car is deeply implicated in the 'shame' of Australian governance. $^{70}$ Survivors appear to remember in detail the cars involved and the thunderous separation:

the six of us were put on the old truck and taken to Oodnadatta which was hundreds of miles away and then we got there in darkness...we didn't see our mother again. She just kind of disappeared into the darkness. $^{71}$

The stolen generation reveals the importance of the car for Australian governance. Not only did the car allow for the precise taking of individual children from their families but was a key element of the myth of possession and future prosperity that conceived that removal was an appropriate response to the child's 'problems.' The car's role in the knowing and ordering of individuals allowed for management through the direct application of the car to the control of an individual's body.

In summary the car appears highly significant in the knowing, ordering and managing of Australians. From knowing, ordering and managing Australians through their car related identity, to ordering and managing individuals through community grounding myths of possession and future prosperity, to the ordering of space from place and to its direct control over bodies, the car is intimately part of Australian governance. Carhuman relations are often expressed as cybernetic. ${ }^{72}$ However, in Australia the cyborg metaphor can be viewed in its logical systemic and networked extreme. Australia should be properly appreciated as the petrochemical, chrome plated cyborg republic of 
Oz.

\section{Conclusion: Cyborg Republic of $\mathrm{Oz}$}

In revealing the cyborg republic of $\mathrm{Oz}$ this paper offers an expanded understanding of governance and provides insights into Australian governance. It shows that study of the knowing, ordering and managing of individuals needs to consider the precise role of technological objects in facilitating certain types of governmental relations. This does not mean a recycling of the common narratives of technological determinism. ${ }^{73}$ Governance is never total and complete. ${ }^{74}$ This means that technology cannot be deployed instrumentally to secure solely desirable and predictable policy outcomes. Failure, resistance and complexity continually interrupt the dreams of social technocrats.

Additionally, this study has ramifications for the study of social and political issues in Australia. It explains the lack of public transport options in Australia and the enormous task facing anti-car activists and public transport policy generally. It explains attitudes towards the unemployed and marginal that assumes a type of mobility that only the car provides. ${ }^{75}$ It even explains the failure of the Australia Card proposal. ${ }^{76}$ That piece of social technology was superfluous in a society where having a drivers licence is so common that it is considered determinative proof of identity for joining a video library, entering pubs, opening bank accounts and accessing welfare services. It also suggests that de-motorisation of Australia would have distinct ramifications for Australian identities, not to mention the Australian retirement and Australian spaces. It also explains contemporary political anxieties. The demarcated distance of place and space seems to reflect a culture that is continually concerned about invading others. Like motorists shocked after an accident, Australians appear beset by demanding others, young aboriginal cars thieves, ${ }^{77}$ native title claimants ${ }^{78}$ or queue jumping asylum seekers, disturbing and interrupting their private journeying. Further, like drivers harassing a traffic cop after an accident, the common appeal is for official vindication and government action. Here the apparatus of government can be viewed as the panel-beater state - straighten the bent sheet metal, keep the road warriors mobile and let the traffic flow. 
In conclusion this paper considered how the car is an important feature in Australian governance; that is in the knowing, ordering and managing of individuals. Given the uniqueness in considering how specific technological objects influence governance the movie Mad Max II was used as a prism to separate out the roles that the car performs in the knowing, ordering and managing of individuals. Having identified the car as identity, car as myth and car as power these foci were transposed to Australian society. Through this analysis the car was revealed as significant for Australian identities, important for myths of cultural possession and future prosperity, essential for the demarcation of space and place, and often deployed to directly control individual bodies. The intimacy of the car for the knowing, ordering and management of Australians can be summarised in the concluding images from Mad Max II. Max's sacrifice has allowed the community to escape the compound and fulfil their mythical destiny. The final frame is of the Feral Child, the future leader of the Great Northern Tribe, holding a metallic boomerang. Here, in this glimpse of the future, the knowing, ordering and managing of individuals that occurred throughout the movie makes perfect sense. The goal of Australian governance is revealed. A child in good health holds an object that symbolises adaptation of technology to the Australian land, ${ }^{79}$ while in the under-laid shot a convoy of cars makes a dusty retreat towards a flat horizon.

\footnotetext{
${ }^{1}$ Lecturer, College of Law, University of Notre Dame Australia, PO Box 1225 Fremantle 6959, Western Australia, AUSTRALIA, ktranter@nd.edu.au. I would like to thank Professor Rosemary Hunter, Lyndal Sleep, Georgina Clarsen and anonymous referees for reviewing drafts of this paper.

${ }^{2}$ The description of the Max's car the Interceptor (in real life an Australian made 1973 XB Ford Falcon coupe), according to one of Papagallo's community.

${ }^{3}$ Geoffrey Blainey, The Tyranny of Distance: How Distance Shaped Australia's History (Melbourne: Sun Books, 1983 (1966)), p. 294.

${ }^{4}$ John Fiske, Bob Hodges and Graeme Turner, Myths of Oz: Reading Australian Popular Culture (Sydney: Allen \& Unwin, 1986), p. 69.

${ }^{5}$ Rose Lucas, 'Dragging it Out: Tales of Masculinity in Australian Cinema, From Crocodile Dundee to Priscilla, Queen of the Desert', Journal of Australian Studies, 56, 1998, pp. 138-146.

${ }^{6}$ Human Rights and Equal Opportunity Commission (HREOC), Bringing them Home: National Inquiry into the Separation of Aboriginal and Torres Strait Islander Children from their Families (Wilson Report) (Canberra: Human Rights and Equal Opportunity Commission, 1997), p. 48.

${ }^{7}$ George Pavlich, 'The Art of Critique or How Not to be Governed Thus', in Gary Wickham and George Pavlich (eds), Rethinking Law, Society and Governance: Foucault's Bequest (Oxford: Hart Publishing, 2001), pp. 141-154, p. 147.

${ }^{8}$ In particular Michel Foucault, Discipline and Punish: The Birth of the Prison (London: Penguin, 1977) and Michel Foucault, 'Governmentality', Ideology and Consciousness, 6, 1979, pp. 5-21.

${ }^{9}$ William Walters, Unemployment and Government: Genealogies of the Social (Melbourne: Cambridge University Press, 2000).

${ }^{10}$ Pat O’Malley, 'Genealogy, Systematisation and Resistance in “Advanced Liberalism', in Gary
} 
Wickham and George Pavlich (eds), Rethinking Law, Society and Governance: Foucault's Bequest (Oxford: Hart Publishing, 2001), pp. 13-25.

${ }^{11}$ Annette Pedersen, 'Governing Images of the Australian Police Trooper', in Gary Wickham and George Pavlich (eds), Rethinking Law, Society and Governance: Foucault’s Bequest (Oxford: Hart Publishing, 2001), pp. 27-42.

${ }^{12}$ Michel Foucault, Technologies of the Self: A Seminar with Michel Foucault (Amherst: University of Massachusetts Press, 1988), p. 18.

${ }^{13}$ O'Malley, p. 17.

${ }^{14}$ For example Jean Baudrillard, 'Crash', Science Fiction Studies, 18, 1991, pp. 313-320, Paul Mason Fotsch, 'Contesting Urban Freeway Stories: Racial Politics and the O.J. Chase', Cultural Studies, 13/1, 1999, pp. 110-137 and Paul Graves-Brown, 'From Highway to Superhighway: The Sustainability, Symbolism and Situated Practices of Car Culture', Social Analysis 41/1, 1997, pp. 64-75.

${ }^{15}$ Drefus and Rabinow emphasis a hostility in Foucault's work towards the cultural study method of searching and ascribing deep meaning to cultural practices. Alternatively, Pedersen uses images of mounted police to gain an insight into the governing of colonial Victoria. The debate stems from scholars demanding that analysis remains pure to Foucault's project of governmentality against scholars only selectively using some of Foucault's insights. See Hubert Dreyfus and Paul Rabinow, Michel Foucault: Beyond Structuralism and Hermeneutics (London: Harvester Press, 1982) pp. 180-182 and Pedersen, 'Governing Images.'

${ }^{16}$ Chistopher Sharrett, 'Myth, Male Fantasy, and Simulacra in Mad Max and The Road Warrior', Journal of Popular Film and Television, 13/2, 1985, pp. 80-91.

${ }^{17}$ Bob Hodge, 'Aboriginal Myths and Australian Culture', Southern Review, 19, 1986, pp. 277-289.

${ }^{18}$ Delia Falconer, 'We Don't Need To Know the Way Home: Selling Australian Space in the Mad Max Trilogy', Southern Review, 27, 1994, pp. 28-44, p. 38.

${ }_{19}$ Ross Gibson, South of the West: Postcolonialism and the Narrative Construction of Australia (Bloomington: Indiana University Press, 1992), p. 160.

${ }^{20}$ Jon Stratton, 'What Made Mad Max Popular: The Mythology of a Conservative Fantasy', Art and Text, 9, 1983, pp. 37-56, pp. 47-48 and Delia Falconer, 'We Don’t Need To Know the Way Home: The Disappearance of the Road in the Mad Max Trilogy', in Steven Cohan and Ina Rae Hark (eds), The Road Movie Book (London: Routledge, 1997), pp. 249-270, pp. 259-260.

${ }^{21}$ Humungus' own description the horde.

${ }^{22}$ See Stratton, Sharrett and Paul Taylor, 'A Culture of Temporary Culture', Art \& Text, 16, 1984, pp. 94-107.

${ }^{23}$ Sharrett, p. 90.

${ }^{24}$ Although it is nuclear in Mad Max III: Beyond Thunderdome were the final scenes are in a postnuclear blast Sydney.

${ }^{25}$ Opening narration. In the closing voiceover viewers realise that the narrator was the "Feral Kid" in old age.

${ }^{26}$ Opening narration.

${ }^{27}$ Gibson, p. 163.

${ }^{28}$ Opening narration.

${ }^{29}$ Peter Fitzpatrick, Modernism and the Grounds of Law (Melbourne: Cambridge University Press, 2001), p. 21).

${ }^{30}$ Sharrett p. 87.

${ }^{31}$ Falconer, 'The Disappearance of the Road', p. 262.

${ }^{32}$ Stratton.

${ }^{33}$ Opening narration.

${ }^{34}$ Falconer, 'Selling Australian Space', p. 38.

${ }^{35}$ Stratton, p. 55.

${ }^{36}$ Sharrett, p. 88.

${ }^{37}$ Stratton, p. 56.

${ }^{38}$ Stratton p. 46.

${ }^{39}$ Roland Barthes, Mythologies (London: Paladin, 1984 (1957)), p. 88.

${ }^{40}$ Linley Walker, 'Under the Bonnet: Car Culture, Technological Dominance and Young Men of the Working Class', Journal of Interdisciplinary Gender Studies, 3/2, 1998, pp. 23-43.

${ }^{41}$ Walker, p. 30.

${ }^{42}$ Glenda Jones, 'Rural Girls and Cars: The Phenomena of 'Blockies’', Rural Society, 2/3, 1991, pp. 16. 
${ }^{43}$ Jones, p. 5.

${ }^{44}$ Greg Noble and Rebecca Baldwin, 'Sly Chicks and Troublemakers: Car Stickers, Nonsense and the

Allure of Strangeness’, Social Semiotics, 11/1, 2001, pp. 75-89, p. 83.

${ }^{45}$ Noble and Baldwin, pp. 84-85.

${ }^{46}$ Richard Lefrancöis, 'Mobility Patterns and Attitudes Toward Driving a Car Among the Elderly

Living in Small Towns and Rural Areas’, Rural Studies, 8/1, 1998, pp. 17-27, p. 26.

${ }^{47}$ Georgine Clarsen, 'Still Moving: Bush Mechanics in the Central Desert', Australian Humanities

Review, March-May, 2002, www.lib.latrobe.edu.au/AHR/archive/Issue-March-2002/Clarsen.htm.

${ }^{48}$ Walker.

49 John William Knott, 'The 'Conquering Car': Technology and Symbolism and the Motorisation of

Australia before World War II’ Australian Historical Studies, 31/114, 2000, pp. 1-26, p. 26

${ }^{50}$ Knott.

${ }^{51}$ Marion Bell's journey was presented as all that more remarkable in that she was woman supposedly unskilled in the manly tasks of car maintenance and exploration. Bell was nothing of the sort, she was an accomplished driver, mechanic and capitalist. See Georgine Clarsen, 'Tracing the Outline of Nation: Circling Australia by Car', Continuum: Journal of Media and Cultural Studies, 13/3, 1999, pp. 359-369, p. 363.

52 Clarsen, 'Tracing the Outline of Nation', pp. 365-366. For another circumnavigation journey from the 1920s see M. H. Ellis, The Long Lead: Across Australia by Motor Car (London, T. Fisher Unwin, 1927).

${ }^{53}$ Anna McGrath, 'Travels to a Distant Past: The Mythology of the Outback', Australian Cultural History, 10, 1991, pp. 113-124, pp. 114-115.

${ }^{54}$ David Williamson, Travelling North (Sydney, Currency Press, 1980), p. 8.

55 Robyn Dowling, Anna Güllner and Bronwyn O’Dwyer, ‘A Gender Perspective on Urban Car Use: A Qualitative Case Study’, Urban Policy Research, 17/2, 1999, pp. 101-110.

${ }^{56}$ Rod Giblett, 'Magician’s Bower: The Car as Communication Technology', Australian Journal of Communication, 27/1, 2000, pp. 15-24, p.16.

${ }^{57}$ Andrew Herrick, 'King Car: On the Road to Auto-Utopia’, Arena Magazine, 38, 1998, pp. 44-46.

${ }^{58}$ Moya Costello, 'Learning to Drive: Reading the Signs', Meanjin, 58/3, 1999, pp. 22-32, p. 26.

${ }^{59}$ In 2000 the car claimed 1823 fatalities or 9.3 fatalities per 100,000 people (Australian Transport Safety Bureau, Road Fatalities Australia 2000 Statistical Summary (Canberra, Australian Transport Safety Bureau, 2001), p. 3).

${ }^{60}$ Anna Haebich, Broken Circles: Fragmenting Indigenous Families 1800-2000 (Fremantle: Fremantle Arts Centre Press, 2000), p. 312 and Tim Rowse, White Flour / White Power: From Rations to Citizenship in Central Australia (Melbourne, Cambridge University Press, 1998), p. 108.

${ }^{61}$ Coral Edwards and Peter Read, The Lost Children: Thirteen Australian taken from their Families tell of the Struggle to Find their Natural Parents (Sydney, Doubleday, 1989), p. 4.

${ }^{62}$ HREOC, p. 142.

${ }^{63}$ Tjalaminu Mia, 'Life in Sister Katie’s Home: An Oral History', Studies in Western Australian History, 22, 2001, pp. 125-134, p. 129.

${ }^{64}$ Carmel Bird, The Stolen Children: Their Stories (Milsons Point: Random House, 1998), p. 85.

${ }^{65}$ HREOC, p. 83.

${ }^{66}$ Bird, p. 105.

${ }^{67}$ Edwards and Read, pp. 78-79.

${ }^{68}$ HREOC, p. 129.

${ }^{69}$ Elaine Lomas, 'When Will They Bring my Tommy Back?’, Aboriginal and Islander Health Worker Journal, 24/4, 2000, 6.

${ }^{70}$ Raimond Gaita, A Common Humanity: Thinking about Love \& Truth \& Justice (Melbourne, Text Publishing, 1999), p. 87.

${ }^{71}$ HREOC, p. 129.

${ }^{72}$ Giblett.

${ }^{73}$ Y.T. Carlisle and D.J. Manning, 'Ideological Persuasion and Technological Determinism', Technology in Society, 21/1, 1999, pp. 81-102, p. 97.

${ }^{74}$ O’Malley, p. 19.

75 Tony Eardly and George Matheson 'Australian Attitudes to Unemployment and Unemployed People’, Australian Journal of Social Issues 35/3, 2000, pp. 181-202.

${ }^{76}$ J. G. Starke, 'The Demise of the Australia Card Bill and the Disallowance of Federal Regulations', Australian Law Journal, 62, 1988, pp. 6-10. 
${ }^{77}$ Quentin Beresford and Paul Omaji, Rites of Passage: Aboriginal Youth, Crime and Justice (Fremantle: Fremantle Arts Centre Press, 1996).

${ }^{78}$ Annette Pedersen, et. al., 'Attitudes Towards Aboriginal Australians in City and Country Settings', Australian Psychologist, 35/3, 2000, pp. 109-117.

${ }^{79}$ Falconer, 'Selling Australian Space', p. 38. 